\title{
Early Childhood Nutrition, Schooling, and Sibling Inequality in a Dynamic Context: Evidence from South Africa
}

\section{Futoshi Yamauchi}

$\mathrm{W}$ hile nutritional intake in early childhood provides the basis for a child's health capital, investments in schooling provide the basis for a child's knowledge capital. That store of knowledge, in turn, will eventually be rewarded in the labor market. Does the good health built up by the child in his early years affect his educational achievement and his future success? This paper addresses that question based on panel data from South Africa.

Studies have shown that health capital and investments in schooling both generate positive economic returns. Health is an input in the schooling investment. For example, if a child is healthy, he will be able to attend school regularly, which will contribute to his progress. In a household where one sibling is less healthy than another, schooling may widen the differences between them. Parents, seeing that their children's health capital is unequal, make judgments about the potential returns to investments in schooling. In the early years, if parents are averse to inequality, they may invest more in schooling for the child with less health capital to help make up the difference between siblings, or they may invest more in the healthy child because the potential returns are greater. As the children become older, however, the healthier child may be able to earn more in the marketplace and thus contribute to the household income. The opportunity cost of keeping that child in school may then be high.

\section{Data and Methodology}

To empirically assess this issue, a

few challenging problems must first be resolved. Household-specific factors that we do not know about may affect both childhood nutrition and schooling decisions. Therefore, to mitigate the effect of this spurious correlation, the use of household fixed effects is required. In the model, human capital accumulation is seen as a sequential process in which health is formed at an early stage of development and schooling investment is undertaken based on the given health outcomes. Both health and knowledge capital determine earnings in the labor market.

This analysis requires data from different points in time for the same individuals. Data are obtained from various years (1993, 1998, and 2004) of an ongoing income dynamics study undertaken by the province of KwaZulu-Natal, which collected information on individuals regarding school enrollment, age started school, grade completed, grades repeated, and expenditures for children of 7 to 20 years old. As a supplement, children 7 to 9 years old were given a simple mathematics test. A height-for-age Z-score of siblings is the measure used to determine whether a child is of normal size and presumably adequately nourished and healthy. The analysis combines nutritional status information for preschool children (ages 0 to 5) for 1993 and 1998 with schooling inputs and outcomes for the same children in 2004.

\section{Findings}

The study finds that nutritional status (based on height) affects schooling in that children of at least normal height tend to start school earlier, complete more grades, and repeat fewer grades. Girls generally do better than boys, although this does not seem to be positively related to the height Z-score. About 5 percent of taller children were not successful in school. Why the height-for-age Z-score should have a negative effect on schooling outcomes for these children is not clear.

The correlation between height and the age the child starts school implies that childhood malnutrition is likely to delay starting school. For the most part, however, the good effects of nutrition and health status on 
primary school outcomes diminish as the child moves from primary to secondary school. An investigation of intrahousehold resource allocation among siblings, using data on school fee expenditures, also indicates that resources often are allocated to children in the early years to reduce inequality, but such expenditures tend to increase inequality at later stages. Whether parents differentiate among their children in the quality of education provided is partially determined by household income. The only options for credit-constrained parents in low-income households may be either to send their children to inexpensive neighborhood schools or not to send them at all.

The simple mathematical test given to children seven to nine years of age consisted of four problems, one each of addition, subtraction, multiplication, and division. As expected, the likelihood of answering correctly rose as age increased. However, height (as a proxy for health) only had a significant positive effect on test results for the seven-year-olds. This implies that early childhood nutrition only improves learning performance when the child first starts school.

The study is complicated by the fact that South Africa was undergoing the transition from apartheid to democracy during the period 1993-96; education was profoundly affected by the shift away from segregated schools. Political struggles were particularly violent in
KwaZulu-Natal in 1994, when data used in this analysis were gathered. Therefore, the nutritional status of preschool children in the province during that turbulent time may well have been affected and may have contributed to differences in the health capital of siblings. The social changes may also have contributed to imprecision in the estimation results.

In sum, the results reported in this paper generally confirm that investments in the nutritional status of very young children increase later gains from education and their future value in the labor market.

Keywords: early childhood nutrition, health capital, height-for-age, schooling investments and outcomes, South Africa

\section{Recent FCND Discussion Papers}

Has economic growth in Mozambique been pro-poor? Robert C. James, Channing Arndt, and Kenneth R. Simler, December 2005 DP202

Community, inequality, and local public goods: Evidence from school financing in South Africa, Futoshi Yamauchi and Shinichi Nishiyama, September 2005 DP201

The full text of this document and other FCND Discussion Papers are available at www.ifpri.org/divs/fend/dp.htm.

For additional information, email ifpri-fen@egiar.org.

Note: This brief is based on an IFPRI division discussion paper containing preliminary material and research results. Division discussion papers have not been subject to formal external reviews managed by IFPRI's Publications Review Committee, but have been reviewed by at least one internal or external researcher. They are circulated in order to stimulate discussion and critical comment.

Copyright $(\subset$ 2006, International Food Policy Research Institute. All rights reserved. Sections of this material may be reproduced for personal and not-for-profit use without the express written permission of but with acknowledgment to IFPRI. To reproduce the material contained herein for profit or commercial use requires express written permission. To obtain permission to reprint, contact the Communications Division at ifpri-copyright@cgiar.org.

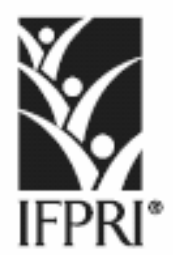

INTERNATIONAL FOOD

POLICY RESEARCH INSTITUTE

sustainable solutions for ending hunger and poverty

2033 K STREET NW

WASHINGTON, DC 20006-1002 USA 